\title{
Analisis Dampak Penggunaan Anggaran Sektor Pertanian Terhadap Pertumbuhan Ekonomi Sektor Pertanian di Provinsi Kalimantan Timur
}

\author{
Mursidah $^{1}$, Midiansyah Effendi ${ }^{2}$, Achmad Zaini $^{3}$ \\ 1,2,3 Fakultas Pertanian, Universitas Mulawarman, Samarinda, Kalimantan Timur \\ 1email: mursidah.spmm@gmail.com \\ 2email: emdiansyah@gmail.com \\ 3email: ach.zaini@gmail.com
}

\begin{abstract}
This research aimed to know the change of budget utilization of agricultural sectors to gross regional domestic product in East Kalimantan Province. The study was conducted for 4 months from July to October 2017. The Research located in Samarinda City. The used data for this study was secondary data which was the time series data for the periode of 2010-2016. Analyzed using multiple linear regression with Least Square Model assumption. The result showed that partially profit of agriculture subsystem of food crops and livestock significantly to gross regional domestic product of agriculture sector in East Kalimantan Province. Simultaneously, agricultural expenditure budget was significant to GDP of agriculture sector in East Kalimantan Province.
\end{abstract}

Kata kunci : Budget, Agricultural sectors, Gross regional domestic product .

\section{ABSTRAK}

Tujuan dari penelitian ini adalah mengetahui dampak perubahan penggunaan anggaran sektor pertanian terhadap PDRB sektor pertanian di Provinsi Kalimantan Timur. Penelitian dilaksanakan selama 3 bulan dari bulan Juli-Oktober 2017. Lokasi penelitian yaitu di Kota Samarinda. Data yang dipergunakan dalam penelitian ini adalah data sekunder yang berupa data time series periode tahun 2010-2016. Alat analisis regresi linier berganda dengan pendekatan Model Kuadrat Terkecil (Ordinary Least Square). Hasil penelitian menunjukkan bahwa secara parsial anggaran belanja subsektor pertanian tanaman pangan dan peternakan berpengaruh signifikan terhadap PDRB sektor pertanian di Provinsi Kalimantan Timur. Sedangkan secara simultan, anggaran belanja sektor pertanian berpengaruh signifikan terhadap PDRB sektor pertanian di Provinsi Kalimantan Timur.

Kata kunci : Anggaran, Sektor Pertanian, PDRB.

\section{Pendahuluan}

\subsection{Latar Belakang}

Pemberlakuan Undang-undang No. 32 tahun 2004 tentang pemerintah daerah dan Undang-undang No. 33 tahun 2004 tentang perimbangan keuangan pemerintah pusat dan daerah, merupakan titik tolak pemberdayaan pemerintah daerah secara lebih mandiri. Kebijakan ini mengartikan bahwa peran yang lebih besar telah diberikan kepada daerah termasuk perencanaan pembangunan di segala sektor. Pola perencanaan pembangunan bersifat desentralistik (buttom up) yang memberikan peluang kepada daerah untuk menentukan arah pembangunannya.

Berhubungan dengan hal tersebut maka pemerintah daerah provinsi atau kabupaten/kota menyusun Anggaran Pendapatan dan Belanja Daerah (APBD) provinsi atau kabupaten/kota guna merencanakan pembangunan. Penyusunan anggaran tersebut 
haruslah ditata dalam suatu sistem anggaran yang mampu meningkatkan penyelenggaraan daerah, baik tugas umum pemerintahan maupun tugas pembangunan.

Pembangunan pertanian memiliki peran yang strategis dalam perekonomian nasional. Peran strategis pertanian tersebut digambarkan melalui kontribusi yang nyata melalui pembentukan kapital, penyediaan bahan pangan, bahan baku industri, pakan dan bioenergi, penyerap tenaga kerja, sumber devisa negara, sumber pendapatan, serta pelestarian lingkungan melalui praktek usahatani yang ramah lingkungan. Berbagai peran strategis pertanian dimaksud sejalan dengan tujuan pembangunan perekonomian nasional yaitu meningkatkan kesejahteraan masyarakat Indonesia, mempercepat pertumbuhan ekonomi, mengurangi kemiskinan, menyediakan lapangan kerja, serta memelihara keseimbangan sumberdaya alam dan lingkungan hidup.

Keberpihakan dan komitmen dari para penentu kebijakan pembangunan, baik di tingkat pusat maupun daerah sangat diperlukan, semuanya tercermin dalam alokasi pendanaan yang besarannya sesuai dengan kebutuhan yang direncanakan. Alokasi anggaran APBD pertanian merupakan cerminan dari keberpihakan dan komitmen para pengambil kebijakan dalam memajukan sektor pertanian di suatu daerah.

Pembangunan pertanian di Kalimantan Timur ditujukan untuk terwujudnya pertumbuhan ekonomi (yang tercemin dari Produk Domestik Regional Bruto atau PDRB) dan kesejahteraan masyarakat. Untuk hal tersebut, dibutuhkan sumber dana yang cukup untuk subsektor Tanaman Pangan, Peternakan, Perkebunan, Perikanan dan Kelautan yang dicerminkan dengan peningkatan nilai PDRB pertanian. Untuk mencapai hal itu, Provinsi Kalimantan Timur menggali dana yang berasal dari anggaran daerah dan meningkatkan produksi pertanian sebagai upaya untuk menggali potensi daerah, yang tentunya akan dapat meningkatkan pendapatan daerah, sehingga akan berdampak terhadap peningkatan pertumbuhan ekonomi daerah.

Perkembangan PDRB pertanian atas dasar harga konstan setiap tahun mengalami perubahan sehingga perlu dilakukan penyusunan. Pertumbuhan positif menunjukkan adanya peningkatan perekonomian, sedangkan pertumbuhan negatif menunjukkan penurunan perekonomian. Peningkatan PDRB pertanian seharusnya berkorelasi positif terhadap alokasi anggaran yang diberikan oleh pemerintah daerah. Peningkatan anggaran sektor pertanian diharapkan akan mendorong PDRB Provinsi Kalimantan Timur semakin meningkat sehingga pertumbuhan ekonomi daerah terus meningkat.

Berdasarkan uraian di atas penulis tertarik untuk membuat penelitian ini dengan judul "Analisis Dampak Penggunaan Anggaran Sektor Pertanian meliputi Anggaran Sub Sektor Pertanian Tanaman Pangan, Perkebunan, Peternakan, Perikanan dan Kelautan Terhadap Pertumbuhan Ekonomi Sektor Pertanian di Provinsi Kalimantan Timur". 


\subsection{Permasalahan yang Diteliti}

Berdasarkan uraian yang telah dikemukakan, maka dapat dirumuskan permasalahan sebagai berikut: bagaimana dampak penggunaan anggaran sub sektor Pertanian terhadap PDRB sektor pertanian di Provinsi Kalimantan Timur?

\subsection{Tujuan Penelitian}

Tujuan yang ingin dicapai dari penelitian ini adalah untuk mengetahui dampak penggunaan anggaran sub sektor Pertanian tanaman pangan, Peternakan, Perkebunan, Perikanan dan kelautan terhadap PDRB sektor pertanian di Provinsi Kalimantan Timur.

\subsection{Manfaat Penelitian}

Melalui penelitian ini, maka diharapkan dapat diambil manfaat penelitian sebagai berikut:

a. Hasil penelitian ini diharapkan dapat memberikan gambaran bagaimana dampak alokasi anggaran APBD sub sektor pertanian (Pertanian tanaman pangan, Peternakan, Perkebunan, Perikanan dan kelautan) terhadap PDRB sektor pertanian di Provinsi Kalimantan Timur.

b. Sebagai bahan referensi dan tambahan pengetahuan bagi pihak lain yang berminat melakukan penelitian lebih lanjut.

\section{Metode Penelitian}

\subsection{Definisi Operasional}

Untuk memperoleh pengertian dan batasan yang lebih jelas mengenai apa yang diteliti sesuai dengan konsep yang telah dikemukakan, maka definisi operasional dapat dijabarkan sebagai berikut:

a. Alokasi anggaran APBD sektor pertanian adalah anggaran APBD Provinsi Kalimantan Timur untuk sub sektor pertanian tanaman pangan, perkebunan, peternakan, perikanan dan kelautan tahun 2010-2016 (Rp tahun $\left.{ }^{-1}\right)$.

b. PDRB pertanian adalah perkembangan PDRB pertanian atas dasar harga konstan Kalimantan Timur pada tahun 2010-2016 (Rp tahun ${ }^{-1}$ ).

c. Harga Konstan adalah penilaian perhitungan yang dilakukan dengan harga satu tahun dasar tertentu, yang dinamakan Atas Dasar Harga Konstan (ADHK).

\subsection{Waktu dan Tempat}

Penelitian dilaksanakan selama 4 bulan, mulai bulan Juli sampai Oktober 2017. Lokasi penelitian yaitu di Kota Samarinda, tepatnya di Badan Pusat Statistik Kalimantan Timur, Dinas lingkup Pertanian (Pertanian tanaman pangan, peternakan, perkebunan, perikanan dan kelautan) Kalimantan Timur, dan BAPPEDA Kalimantan Timur.

\subsection{Metode Pengumpulan Data}


Data yang dipergunakan dalam penelitian ini adalah data sekunder yang berupa data time series periode tahun 2010-2016.

Data ini meliputi data alokasi anggaran APBD pertanian (Pertanian tanaman pangan, peternakan, perkebunan, perikanan dan kelautan) dan data PDRB. Disamping itu, data-data lain yang terkait juga akan digali guna menunjang sempurnanya penelitian ini. Data ini diperoleh dari Badan Pusat Statistik Kalimantan Timur, Dinas lingkup pertanian (Pertanian tanaman pangan, peternakan, perkebunan, perikanan dan kelautan) Kalimantan Timur, dan BAPPEDA Kalimantan Timur serta referensi lainnya.

\subsection{Metode Analisis Data}

Model yang digunakan untuk menganalisa pengaruh alokasi anggaran APBD pertanian (Pertanian tanaman pangan, peternakan, perkebunan, perikanan dan kelautan) terhadap PDRB sektor pertanian di Provinsi Kalimantan Timur adalah dengan menggunakan alat analisis regresi linier berganda dengan pendekatan Model Kuadrat Terkecil (Ordinary Least Square).

Adapun model persamaan yang digunakan dalam penelitian ini adalah

$$
Y=b_{0}+b_{1} X_{1}+b_{2} X_{2}+b_{3} X_{3}+b_{4} X_{4}+e
$$

Dimana :

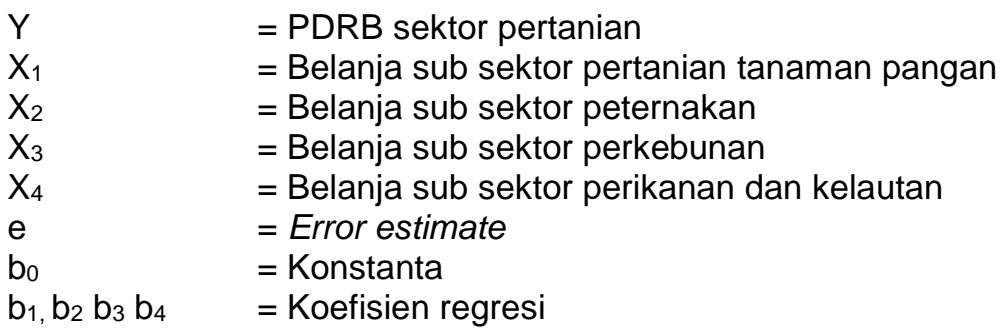

Menurut Supranto (1988), untuk mengetahui besarnya persentase pengaruh variabel bebas $(\mathrm{X})$ terhadap variabel tak bebas $(\mathrm{Y})$ dihitung koefisien determinasi regresi linier berganda dengan rumus:

$$
\mathrm{r}^{2}=\frac{\left.\mathrm{b}_{1} \sum x 1 y \bar{i}+b_{2} \sum x 2 y \mathrm{i}\right)}{\Sigma y^{2}}
$$

Menurut Supranto (1994), untuk mengetahui hubungan antara variabel bebas dengan variabel tak bebas secara keseluruhan maka dilakukan pengujian hipotesis dengan menggunakan uji $\mathrm{F}$ melalui tabel sidik ragam, sebagai berikut:

$$
\mathrm{F}_{\text {hit }}=\frac{\text { KTR }}{K T S}
$$

Keterangan :

KTR = Kuadrat Tengah Terkecil

KTS = Kuadrat Tengah Sisa

Tabel 1. Sidik Ragam

\begin{tabular}{ccccc}
\hline Sumber Keragaman & Db & Jumlah Kuadrat & Kuadrat Tengah & FHit \\
\hline Regresi & $\mathrm{K}$ & JKR & KTR & KTR/KTS \\
Sisa & $\mathrm{n}-\mathrm{k}-1$ & JKS & KTS & \\
\hline Total & $\mathrm{n}-1$ & JKT & & \\
\hline
\end{tabular}


Hipotesis :

$H_{0}: b_{1}=b_{2}=b_{3}=0$, (secara bersama-sama tidak ada pengaruh/hubungan yang signifikan antara $\mathrm{X}_{1}, \mathrm{X}_{2}, \mathrm{X}_{3}$ terhadap $\mathrm{Y}$ ).

$H_{a}: b_{1} \neq b_{2} \neq b_{3} \neq 0$, (secara bersama-sama ada pengaruh/hubungan yang signifikan antara $X_{1}, X_{2}, X_{3}$ terhadap $Y$ )

Kaidah keputusan :

a. Bila $\mathrm{F}$ hit $<\mathrm{F}$ tabel $(\alpha=0,05)$, maka $\mathrm{H}_{0}$ diterima dan $\mathrm{H}_{\mathrm{a}}$ ditolak (belanja sektor pertanian tidak berpengaruh signifikan terhadap PDRB sektor pertanian di Propinsi Kalimantan Timur)

b. Bila $F$ hit $>F$ tabel $(\alpha=0,05)$, maka $\mathrm{H}_{0}$ ditolak dan $\mathrm{H}_{\mathrm{a}}$ diterima (belanja sektor pertanian berpengaruh signifikan terhadap PDRB sektor pertanian di Propinsi Kalimantan Timur)..

Kemudian untuk mengetahui pengaruh antara masing-masing faktor yang mempengaruhi digunakan rumus uji t, yaitu sebagai berikut :

$$
t_{\text {hit }}=\frac{b i}{s=(b i)}
$$

dimana:

$$
\text { Se }(b 1)=\sqrt{\operatorname{var}(b 1)}
$$

dimana:

$$
\operatorname{var}(\mathrm{b} 1)=5 e^{2} \cdot \frac{\Sigma \times 2^{2}}{\left(\Sigma \times 1^{2}\right)\left(\Sigma \times 2^{2}\right)(\Sigma \times 1 \times 2)^{2}}
$$

dimana:

$$
\operatorname{Se}\left(b_{2}\right)=\sqrt{\operatorname{var}\left(b_{2}\right)}
$$

dimana:

$$
\operatorname{var}(\mathrm{b} 2)=5 e^{2} \cdot \frac{\sum x 1^{2}}{\left(\Sigma x 1^{2}\right)\left(\Sigma x 2^{2}\right)(\Sigma x 1 x 2)^{2}}
$$

dimana:

$$
5 e^{2}=\frac{\sum y i^{2}-b_{1} \sum x y_{1}-b 2 \sum x 2 y}{n-3}
$$

Keterangan :

thit $\quad=$ nilai pengujian

$\mathrm{b}_{\mathrm{i}} \quad=$ koefisien regresi

Se $\left(b_{i}\right)=$ standar eror $b_{i}$

$\mathrm{Se} \quad=$ standar eror

Var $=$ varian

Hipotesis :

$H_{0}: b_{i}=0$, (tidak ada pengaruh yang signifikan antara $X$ terhadap $Y$ )

$H_{0}: b_{i} \neq 0$, (ada pengaruh yang signifikan antara $X$ terhadap $Y$ )

Kaidah keputusan : 
a. Jika $t_{\text {hitung }}>t_{\text {tabel }}(\alpha=0,05)$ maka $\mathrm{H}_{0}$ ditolak $\mathrm{H}_{\mathrm{a}}$ diterima, berarti:

Belanja Sektor pertanian (masing-masing sub sektor pertanian tanaman pangan, atau peternakan, atau perkebunan atau perikanan dan kelautan) berpengaruh nyata terhadap PDRB sektor pertanian.

b. Jika $t_{\text {hitung }} \leq t_{\text {tabel }}(\alpha=0,05)$ maka $\mathrm{H}_{0}$ diterima $\mathrm{H}_{\mathrm{a}}$ ditolak, berarti:

Belanja sektor pertanian (masing-masing sub sektor pertanian tanaman pangan, atau peternakan, atau perkebunan atau perikanan dan kelautan) tidak berpengaruh nyata terhadap PDRB sektor pertanian.

\section{Hasil dan Pembahasan}

\section{PDRB Provinsi Kalimantan Timur}

Pertumbuhan ekonomi tercermin dari PDRB. Berikut ini adalah PDRB Kalimantan Timur sektor pertanian atas dasar harga konstan tahun 2010-2016 :

Tabel 2. PDRB Kalimantan Timur Sektor Pertanian Atas Dasar Harga Konstan 2000 (000.000 Rp) tahun 2010-2016 (seri 2010)

\begin{tabular}{|c|c|}
\hline Tahun & PDRB Sektor Pertanian \\
\hline 2010 & $21.167 .771,40$ \\
\hline 2011 & $22.292 .613,29$ \\
\hline 2012 & $23.991 .786,45$ \\
\hline 2013 & $25.535 .674,75$ \\
\hline 2015 & $27.267 .196,98$ \\
\hline 2016 & $28.506 .913,59$ \\
\hline
\end{tabular}

Sumber : BPS Kaltim (2017)

Pada tahun 2010 PDRB Kaltim sektor pertanian mencapai Rp.21,168 Triliun mengalami peningkatan dari tahun ke tahun, hingga tahun 2016 mencapai Rp 28,639 triliun

\section{Pengaruh belanja sektor pertanian terhadap pertumbuhan ekonomi sektor pertanian}

Berdasarkan hasil analisis diketahui bahwa belanja sektor pertanian (meliputi subsektor pertanian tanaman pangan, subsektor peternakan, subsektor perkebunan dan subsektor perikanan dan kelautan) secara bersama-sama berpengaruh signifikan terhadap PDRB sektor pertanian Kalimantan Timur.

Untuk tiap subsektor dapat dijelaskan sebagai berikut :

\section{a. Sektor Pertanian Tanaman Pangan}

Berdasarkan hasil analisis variabel belanja subsektor pertanian tanaman pangan berpengaruh positif dan signifikan terhadap PDRB sektor pertanian. Hal ini didasari atas hasil pengujian statistik jika terjadi peningkatan 1 rupiah belanja subsektor pertanian tanaman pangan akan berdampak pada peningkatan PDRB sektor pertanian sebesar 0,0001 juta rupiah. Hasil penelitian ini sejalan dengan temuan Syaifuddin (2013) bahwa sub sektor tanaman pangan pada dasarnya memiliki keunggulan komparatif dan keunggulan kompetitif untuk memacu pertumbuhan ekonomi daerah. Sektor pertanian 
menjadi sektor unggulan bagi daerah (Novrilasari, 2008). Temuan Rifai (2012) bahwa peranan pengeluaran pemerintah sektor pertanian tanaman pangan berdampak pada peningkatan PDB.

Pada tahun 2010 anggaran sub sektor pertanian tanaman pangan sebesar Rp 56.917.922.410, tahun 2011 Rp 52.413.219.622. Pada tahun 2012 anggaran belanja sub sektor pertanian tanaman pangan sebesar Rp 80.417.743.335, tahun 2013 sebesar $R p$ 107.851.760.000 dan pada tahun 2014 sebesar Rp 138.968.320.325. Pada tahun 2015 mengalami penurunan menjadi Rp 136.253.829.913 dan berkurang lagi menjadi Rp 99.279.796.016 pada tahun 2016.

Berdasarkan luas pengusahaan, baik untuk lahan sawah maupun lahan bukan sawah, masih banyak peluang untuk mengusahakan tanaman pangan (padi, palawija dan hortikultura) di Kalimantan Timur. Namun demikian disadari masih ditemui adanya kendala dalam upaya pengembangannya. Kendala yang dijumpai diantaranya adalah mengenai keterbatasan SDM dan Infrastruktur.

Sebagaimana diketahui SDM pertanian dalam hal ini petani, rata-rata tingkat pendidikannya masih relatif rendah, hal ini menghambat pada adopsi teknologi dan inovasi di Bidang Pertanian ditambah lagi dengan terbatasnya jumlah petani yang ada bila dibandingkan dengan potensi lahan yang tersedia, sehingga kedepan perlu diupayakan peningkatan keterampilan petani melalui pembinaan dan pelatihan-pelatihan keterampilan bagi petani.

Masalah lain yang dihadapi petani adalah terjadinya rantai pemasaran yang cukup panjang dari produsen ke konsumen, sehingga margin yang diterima petani rendah, sehingga secara ekonomis usaha taninya kurang menguntungkan. Dalam upaya pengembangan usaha pertanian ke depan perlu adanya keterpaduan program baik internal.

\section{b.Subsektor peternakan}

Berdasarkan hasil analisis variabel belanja subsektor peternakan berpengaruh positif dan signifikan terhadap PDRB sektor pertanian. Hal ini didasari atas hasil pengujian statistik jika terjadi peningkatan 1 rupiah belanja subsektor peternakan akan berdampak pada peningkatan PDRB sektor pertanian sebesar 0,0001 juta rupiah.

Pembangunan peternakan merupakan bagian dari pembangunan pertanian dan pembangunan wilayah pada hakekatnya adalah upaya untuk dapat (1) menyediakan pangan asal ternak yang cukup kualitas dan kuantitas, (2) memberdayakan sumberdaya manusia peternakan agar dapat menghasilkan produk yang berdaya saing tinggi dalam dan luar negeri, (3) menciptakan peluang ekonomi untuk meningkatkan pendapatan peternak, (4) menciptakan lapangan kerja di bidang agribisnis peternakan, (5) melestarikan dan memanfaatkan sumber daya alam pendukung peternakan, (6) menggali 
protensi di bidang peternakan. Oleh karena itu paradigma baru pembangunan peternakan tidak lagi menempatkan peternak hanya sebagai objek, tetapi sekaligus sebagai subjek pembangunan yang berperan sebagai pelaku ekonomi penting.

Peningkatan kebutuhan asal ternak akan terus meningkat sejalan dengan pertumbuhan penduduk dan pola konsumsi, sebagai wujud dari peningkatan kesejahteraan masyarakat. Secara global konsumsi masyarakat akan bergeser dari konsumsi sereal ke daging seiring dengan meningkatnya income per kapita masyarakat. Sistem pangan di era globalisasi akan lebih mengarah pada produk-produk pangan olahan.

Jumlah anggaran belanja sub sektor peternakan pada tahun 2010 adalah sebesar Rp 36.253.662.821, pada tahun 2011 sebesar Rp 43.539.285.911, pada tahun 2012 sebesar Rp 51.580.426.032. Jumlah anggaran belanja sub sektor peternakan tanaman pangan mengalami peningkatan sampai dengan tahun 2013 sebesar Rp 73.329.718.000. Pada tahun 2014 jumlah anggaran belanja sub sektor peternakan sebesar Rp 67.517.958.264. Mengalami kenaikan pada tahun 2015 menjadi Rp 80.919.778.041 dan pada tahun 2016 kembali menurun

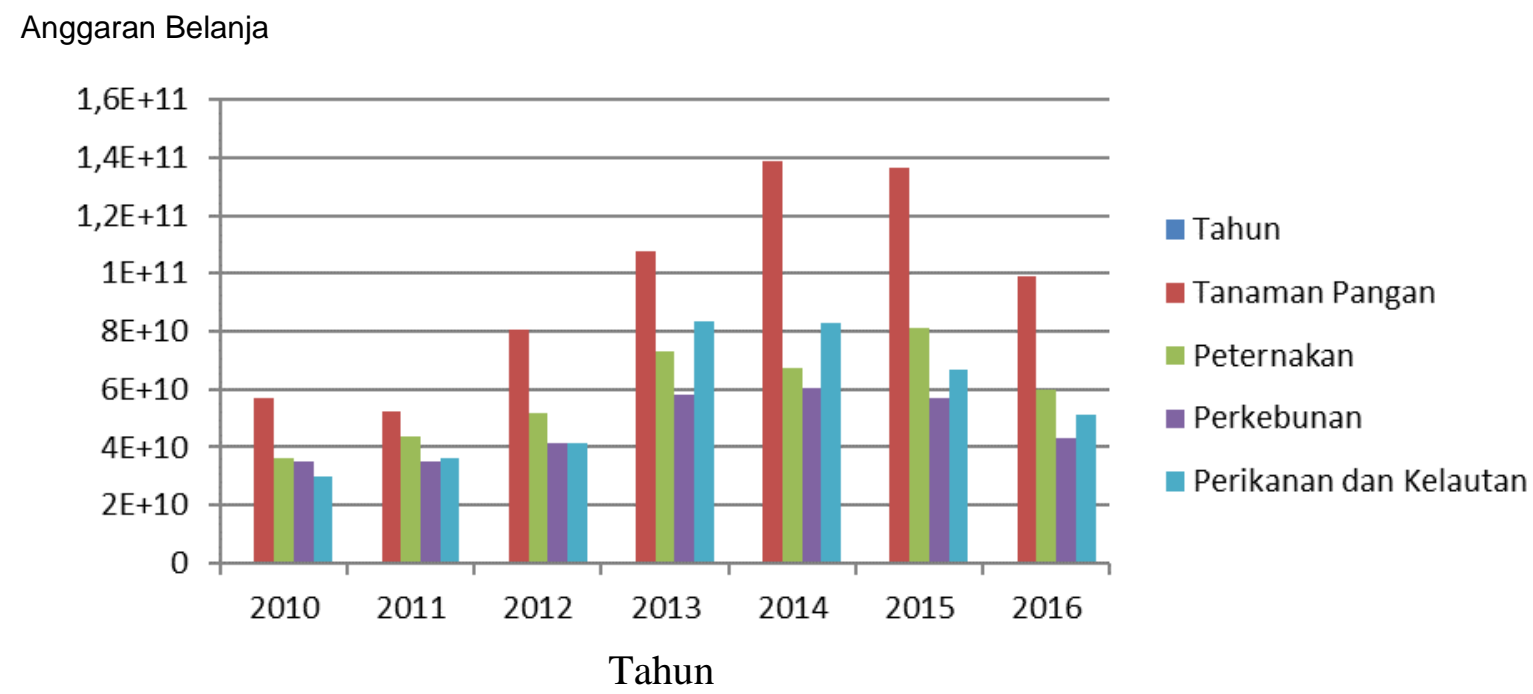

Gambar 1. Anggaran Belanja Sektor Pertanian Tahun 2010-2016 Untuk Tiap Subsektor.

\section{c. Subsektor perkebunan}

Berdasarkan hasil analisis variabel belanja subsektor perkebunan berpengaruh negatif dan tidak signifikan terhadap PDRB sektor pertanian. Hal ini didasari atas hasil pengujian statistik jika terjadi peningkatan 1 rupiah belanja subsektor perkebunan akan berdampak pada penurunan PDRB sektor pertanian sebesar 0,001 juta rupiah.

Sektor perkebunan mempunyai peranan yang sangat penting baik dalam pengembangan wilayah, ekonomi, sosial maupun ekologi. Peranan tersebut semakin penting karena perkebunan merupakan sektor yang berbasis sumber daya alam yang 
tidak tergantung pada komponen impor, sehingga lebih mampu menghadapi gejolak ekonomi global.Jenis-jenis komoditas unggulan perkebunan yang dikembangkan di Kalimantan Timur diantaranya adalah kelapa sawit, karet, kakao, lada, dan kelapa dalam.

Jumlah anggaran belanja sub sektor perkebunan pada tahun 2010 sebesar Rp 34.817.184.800 dan mengalami peningkatan jumlah anggaran pada tahun 2011 sebesar Rp 35.184.611.917. Pada tahun 2012 Rp 41.713.688.676, tahun 2013 jumlah anggaran sebesar Rp 58.277.708.000 dan mengalami peningkatan sampai dengan tahun 2014 sebesar Rp 60.571.250.878. Menurun menjadi Rp 57.033.594.500 pada tahun 2015 dan Rp 43.419.618.200 pada tahun 2016.

\section{d. Subsektor perikanan dan kelautan}

Berdasarkan hasil analisis variabel belanja subsektor perikanan dan kelautan berpengaruh positif, tetapi tidak signifikan terhadap PDRB sektor pertanian. Hal ini didasari atas hasil pengujian statistik jika terjadi peningkatan 1 rupiah belanja subsektor perikanan dan kelautan akan berdampak pada peningkatan PDRB sektor pertanian sebesar 0,0001 juta rupiah.

Sektor perikanan di Kalimantan Timur diharapkan dapat menjadi sektor unggulan bagi pertumbuhan ekonomi Kalimantan Timur khususnya dan Indonesia pada umumnya. Sumberdaya perikanan merupakan sumberdaya yang dapat diperbaharui (renewable resources) dan relatif ramah terhadap lingkungan hidup apabila dikelola secara baik. Sektor perikanan di Kalimantan Timur diharapkan dapat menjadi sektor unggulan bagi pertumbuhan ekonomiKalimantan Timur khususnya dan Indonesia pada umumnya.

Anggaran belanja sektor perikanan dan kelautan tahun 2010 sebesar Rp 30.000.000.000 kembali mengalami peningkatan pada tahun 2011 sebesar Rp 36.245.332.300 sampai dengan tahun 2013 sebesar Rp 83.510.391.000 dan pada tahun 2014 sebesar Rp 82.920.622.111. Pada tahun 2015 dan 2016 mengalami penurunan, masing-masing sebesar Rp 66.939.079.858 dan Rp 51.445.146.174.

Sumberdaya perikanan merupakan sumberdaya yang dapat diperbaharui (renewable resources) dan relatif ramah terhadap lingkungan hidup apabila dikelola secara bijaksana. Potensi yang dimanfaatkan dengan baik dapat menyumbangkan terhadap pertumbuhan GDP nasional dan regional serta memberikan kontribusi yang cukup besar terhadap devisa serta tingkat pendapatan nelayan/petani ikan di kabupaten dan kota, karena harga beberapa komoditi perikanan seperti udang baik udang beku maupun udang segar yang menjadi primadona perikanan dan beberapa jenis ikan bernilai ekonomis tinggi yang diekspor cenderung mengikuti fluktuasi nilai tukar Rupiah terhadap Dollar Amerika.

Kalimantan Timur memiliki potensi sumberdaya ikan yang cukup besar, diantaranya: 
- Wilayah ZEEI (Zona Ekonomi Eksklusif Indonesia) di laut Sulawesi seluas $+297.813 \mathrm{Km} 2$.

- Wilayah penangkapan dipantai seluas $+44.892,8 \mathrm{Ha}$.

- Hutan mangrove yang dapat dikonversi untuk budidaya air payau seluas $+447.000 \mathrm{Ha}$.

- Perairan umum seluas +2.773.937 Ha.

\section{Kesimpulan dan Saran}

\subsection{Kesimpulan}

Belanja subsektor pertanian dan tanaman pangan dan subsektor peternakan berpengaruh positif dan signifikan terhadap pertumbuhan ekonomi sektor pertanian Kalimantan Timur. Secara keseluruhan, belanja sektor pertanian berpengaruh sigifikan terhadap pertumbuhan ekonomi sektor pertanian Kalimantan Timur.

\subsection{Saran}

Diharapkan agar peningkatan belanja sub sektor tanaman pangan dapat dijadikan sebagai penyedia bahan baku untuk industri pertanian agar memiliki nilai tambah serta meningkatkan tingkat kesejahteraan masyarakat di Kalimantan Timur. Diperlukan pengembangan sub sektor tanaman pangan dengan menjadikan daerah-daerah tertentu menjadi pusat produksi sub sektor tanaman pangan yang unggul. Sub sektor peternakan sebagai sub sektor dari pertanian yang harus dimaksimalkan baik dari aspek belanja daerah maupun penggunaan outputnya, agar menjadi bahan baku produksi yang berkualitas sehingga memacu pertumbuhan ekonomi daerah. Pembangunan sub sektor perkebunan harus mengedepankan potensi kawasan dan kemampuan sumber daya manusia di daerah. Selain peningkatan belanja pemerintah daerah pada sub sektor ini, peran pemerintah daerah juga diharapkan untuk memberdayakan masyarakat agar dibina secara berkelanjutan sebagai petani perkebunan yang berpengetahuan dan mandiri. Diharapkan pada peningkatan program pembibitan dan usaha perikanan dan karantina ikan yang didukung dengan pendanaan yang proporsional dari pemerintah daerah. Pentingnya kebijakan untuk memproteksi nelayan tradisional di Kalimantan Timur.

\section{Daftar Pustaka}

Alfrita Junain Sade. 2011. Analisis Pengaruh Beberapa Faktor Terhadap PDRB dan Penyerapan Tenaga Kerja di Kalimantan Timur

Badan Pusat Statistik. 2016. Kalimantan Timur Dalam Angka 2016. Badan Pusat Statistik Provinsi Kalimantan Timur. Samarinda..

Badan Pusat Statistik. 2016. Statistik Keuangan Pemerintah Provinsi dan Pemerintah Kabupaten/Kota Kalimantan Timur. Badan Pusat Statistik Provinsi Kalimantan Timur. Samarinda. 
Boediono. 1985. Pengantar ekonomi mikro. Fakultas Ekonomi UGM, Yogyakarta.

Chidinma, Ebere \& Kemisola, Osundina. 2012. Goverment Expenditure on Agriculture and Economic Growth in Nigeria. International Journal of Science and Research (IJSR) Babbock University Ogun State Nigeria.

Danarti dan S. Najiati. 1995. Palawija budidaya dan analisis usahatani. Penebar Swadaya, Jakarta.

Daniel, E dan T. Haerani. 1994. Penuntun belajar ekonomi I. Ganeca Exact, Bandung.

Daniel, Moehar. 2004. Pengantar ekonomi pertanian. Bumi Aksara. Jakarta.

Gilarso, T. 1992. Pengantar ekonomi bagian mikro. Kanisius, Yogyakarta.

Jorgenson, Dale. 1963. Capital Theory and Investment Behaviour. American Economic Review Vol. 53, pp $49-58$.

Hanke, J. E., D. W. Wichern dan A. G. Reitsch. 2003. Peramalan bisnis. Prenhallindo, Jakarta.

Ibrahim, M. Y. 2003. Studi kelayakan bisnis. Rineka Cipta, Jakarta.

Ida, Hantika. 2001. Majalah tambang Indonesia. Bumi Aksara. Jakarta.

Kasmir dan Jakfar. 2003. Studi kelayakan bisnis. Kencana, Jakarta.

Kelana, S. 1994. Ekonomi mikro. Rajawali Persada, Jakarta.

Kementerian Pertanian. 2009. Rancangan rencana strategis kementerian pertanian tahun 2010-2014.

Kuncoro, M. 2010. Ekonomi pembangunan. Erlangga. Jakarta.

Lisa Hasliana (2007). Pengarus investasi swasta, investasi pemerintah Terhadap Kesempatan Kerja di Kalimantan Timur. Program Pasca Sarjana Universitas Mulawarman, Samarinda.

Mardiasmo. 2002. Otonomi dan manajemen keuangan daerah. Andi. Yogyakarta.

Maros, Ika. 2009. Pengembangan tanaman pangan. Gramedia. Jakarta.

Mubyarto. 1994. Pengantar ekonomi pertanian. LP3ES, Jakarta.

Rita, dkk. 2009. Kebijakan Pemda dalam alokasi anggaran dan penyusunan Perda untuk mengakselerasi pembangunan pertanian. Proposal Operasional T.A. 2010. Pusat Analisis Sosial Ekonomi dan Kebijakan Pertanian. Badan Penelitian dan Pengembangan Pertanian, Departemen Pertanian.

Rizak, Basri. 2005. Peranan sektor agroindustri terhadap pendapatan dan kesempatan kerja di Sulawesi Selatan. Disertasi. Univ. Hasanudin, Makassar.

Sudarso. 1992. Pengantar ekonomi mikro. Rineka Cipta, Jakarta.

Situngkir, Anggiat. 2009. Pengaruh pertumbuhan ekonomi, pendapatan asli daerah, dana alokasi umum dan dana alokasi khusus terhadap anggaran belanja modal pada Pemko/Pemkab Sumatera Utara. Tesis. Universitas Sumatera Utara, Medan.

Soekartawi, dkk. 1986. Ilmu usaha tani dan penelitian untuk pengembangan petani kecil. Universitas Indonesia. Jakarta.

Soekartawi. 1994. Teori ekonomi produksi dengan pokok bahasan analisis fungsi CobbDouglas. Raja Grafindo Persada, Jakarta.

Sudjana. 1996. Metode statistik. Tarsito, Bandung.

Sukirno, S. 1994. Pengantar teori mikro ekonomi. Rajawali Persada, Jakarta.

Suparmoko dan Irawan. 2002. Ekonomika pembangunan. BPFE-Yogyakarta. Yogyakarta. 
Supranto, J. 1988. Ekonometrika. Universitas Indonesia. Jakarta.

Supranto, J. 1994. Metode peramalan kuantitatif untuk perencanaan. Gramedia. Jakarta.

Tohir, K. A. 1993. Pengantar ekonomi pertanian. Sumur, Bandung. 